\title{
Undetected patricide: Inaccuracy of cause of death determination without an autopsy
}

\author{
Carlo P. Campobasso ${ }^{\text {a, * }}$, Domenica Laviola ${ }^{\text {b }}$, Ignazio Grattagliano c, Luigi Strada ${ }^{\text {, }}$ \\ Alessandro S. Dell'Erba ${ }^{b}$ \\ a Dept. of Medicine and Health Sciences, University of Molise, via De Sanctis, 86100 Campobasso, Italy \\ b Section of Legal Medicine, Dep of Interdisciplinary Medicine (DIM), University of Bari, Policlinico, Piazza Giulio Cesare, 70124 Bari, Italy \\ c Section of Forensic Psychiatry, Dep of Interdisciplinary Medicine (DIM), University of Bari, Policlinico, Piazza Giulio Cesare, 70124 Bari, Italy
}

\section{A R T I C L E I N F O}

\section{Article history:}

Received 7 February 2015

Received in revised form

5 May 2015

Accepted 20 May 2015

Available online 30 May 2015

\section{Keywords:}

Patricide

Parricide

Death investigation

Post-mortem external body examination

Forensic autopsy

Stab wounds

\begin{abstract}
A B S T R A C T
Patricide (killing the father) is uncommon form of homicide. Usually the assaults occur at home in the absence of witnesses and adult sons are frequently involved. Homicides in a domestic context usually do not tend to recurrence, because the motivation for the crime ends with the death of the parent. However, this is not what was observed in the present case study dealing with the death of a 70 years old white man originally misclassified as accident and discovered three years later only after an additional homicide in a family context of a 60 years old white lady. Multiple stab wounds to the neck and thorax were misinterpreted at the external male body examination as blunt trauma falling down stairs. No forensic autopsy was requested and no comparison of medical findings with the results from the death scene, such as a bloodstain analysis was performed by the police officers nor required by the judicial authority. This was quite surprising because an additional but preliminary post-mortem external examination performed by a general practitioner on the male body already raised the suspicion that the external lesions were stab wounds thus requiring a forensic autopsy. Only the exhumation of the elderly body, performed years later, confirmed the diagnostic hypothesis raised by the first physician. The present case is quite representative of a death investigation not run professionally and performed by individuals with no specific training where most of the medico-legal investigations (especially for traumatic and violent deaths) are restricted to an external body examination without subsequent autopsy. Although misinterpretation of external lesions is inevitable and significant discrepancies between external body examination and forensic autopsy are not rare, in the case of contradictory results of postmortem external examination or unclear/suspicious cause and manner of death, investigation should proceed necessarily with a forensic autopsy.
\end{abstract}

๑) 2015 Elsevier Ltd and Faculty of Forensic and Legal Medicine. All rights reserved.

\section{Introduction}

Patricide can be simply defined as the act of killing the father. It is a sub-form of parricide which means killing one or both parents. ${ }^{1}$ Patricide has fascinated the public since antiquity representing an abomination in the natural order of things and, in particular, of familial relationships. For this reason it has commonly raised significant interest from the media and the scientific community. ${ }^{2}$ However, patricide is a rare form of

\footnotetext{
* Corresponding author. Tel.: +390874 404 776; fax: +39 0874404778.

E-mail addresses: carlo.campobasso@unimol.it,_cpcarlo@yahoo.com (C.P. Campobasso).
}

homicide covering only a small percentage of all homicides committed.

In Europe, where a significant downward trend of intentional killings has been recently reported, ${ }^{3}$ parricides accounted for $2-3 \%$ of all homicides which is consistent with studies in the USA. Based on the FBI Crime Report 2012, ${ }^{4}$ approximately $1.5 \%$ of the homicides involved parents as victims and a gradually declining trend has been observed over the past years. ${ }^{5}$ However, in 2012 the rate of homicides per 100 thousand inhabitants in USA still remained much higher $(4.7 \%)$ than the European one $(1.2 \%){ }^{3,4}$ It has been calculated that about 5 parents are killed by their biological children in the US every week and approximately more than one hundred offenders are arrested on the average each year in connection with the killings of parents. ${ }^{6,7}$ In Italy, since 2000 
mother and fathers constitute $2-3 \%$ of all murder victims, with the rate of matricide being significantly higher (59\%) than patricide. This is quite interesting considering that in Italy the total number of intentional homicides has reported a tremendous decline from 1.633 totally in 1990 to 526 in 2012 with a rate per 100 thousand inhabitants dropping from $3.38 \%$ to $0.89 \%$, below the European rate. $^{8,9}$

It is not possible to predict violent behavior and, in particular, a parricide since little information is available on this specific topic. Limitations of research studies are mainly related to the infrequency of such crimes and low number of victims. ${ }^{10}$ To the best of our knowledge, usually the assaults occur at home, in the absence of witnesses, and adult sons are frequently involved. ${ }^{11}$ The offender can be also a child or a juvenile/adolescent. When a minor commits parricide, he/she usually does in a cold and calculated manner ${ }^{12}$ avoiding confrontation with the victim. For example, when the parent is sleeping, watching television, or engaged in some other activity. In a large proportion the perpetrator lives with the victim. Men are more likely to kill their parents than women. ${ }^{13}$ Adult sons with psychiatric problems are also often found not criminally responsible because of incapable of appreciating the nature of the act due to the mental disorder. Schizofrenia is common, followed by depression. ${ }^{14}$ Relationship between father/mother and sons often is cruel and abusive due to sexual or physical abuse. ${ }^{15}$ Other than previous history of violence, additional risk factors include the abuse of alcohol or other substances either by the victim or by the perpetrator and conflicts related to financial issues. ${ }^{10,11}$ The most frequently-used instruments are firearms (mainly in patricides), followed by sharp instruments (mainly in matricides). ${ }^{16}$

Finally and this is very interesting, homicides in a family context usually do not tend to recur, because the motivation for the crime ends with the death of the parent. ${ }^{11,17}$ Therefore, father or mother are often the only victim. But this is not what was observed in the following undetected patricide only discovered with the subsequent murder of a lady.

\subsection{Case 1}

In a small town located in the inner central part of Italy (Molise County), a morning day of September, the body of a 60 years old white lady was found on the bloodstained floor of her stationary store by her son-in-law. At autopsy, the cause of death was a combination of two stab wounds on the left side of the neck and blunt force injuries to the left side of the head with underlying depressed skull fractures from blows with a hammer (Figs. 1 and 2 ). In particular, although around the stab wounds there was also an additional incised wound commonly longer than deep, the depth of the main ones was enough to damage the anterior wall of the external carotid artery soon after the origin and the superior thyroid artery totally lacerated soon after the emergence at the level of the hyoid bone. Among the other vascular lesions, also the superficial temporal artery and the occipital artery were damaged by the blunt injuries to the head explaining the bleeding to death. The manner of death was classified as homicide. This was consistent with the evidence collected by blood pattern analysis. At the scene medium velocity impact blood spatter, commonly associated with beatings and stabbings, were found along with blood pooling. A first point/area of convergence of blood source was identified close to a drag pattern showing movement across blood pooling on the floor, where the person was originally assaulted near a copy machine (Fig. 3). Extensive radiating pattern of medium velocity impact blood spatter was found on the floor, on the boxes and the copy machine close to the body along with multiple cast-off bloodstain patterns released from the hammer in motion during the back and forward swing. Projected bloodstains

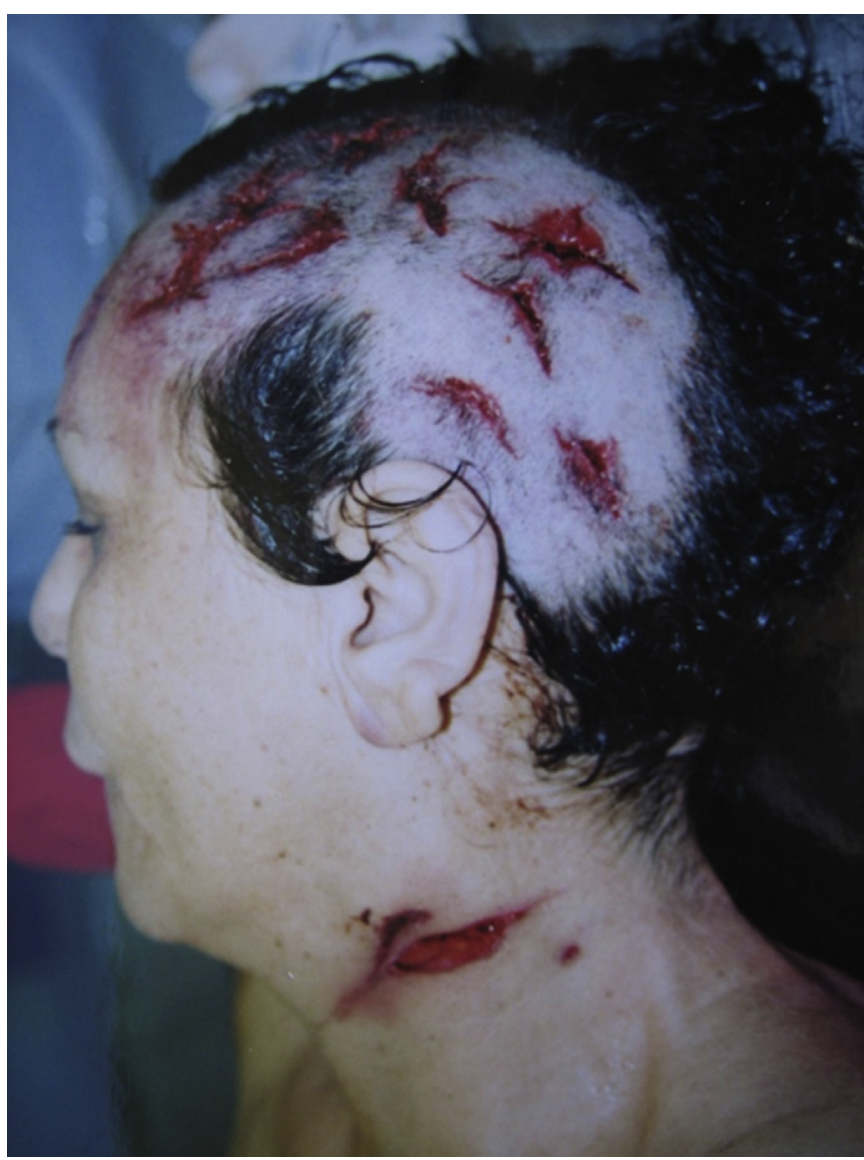

Fig. 1. Blunt force injuries to the head from multiple hammer blows, and stab wounds on the left side of the neck.

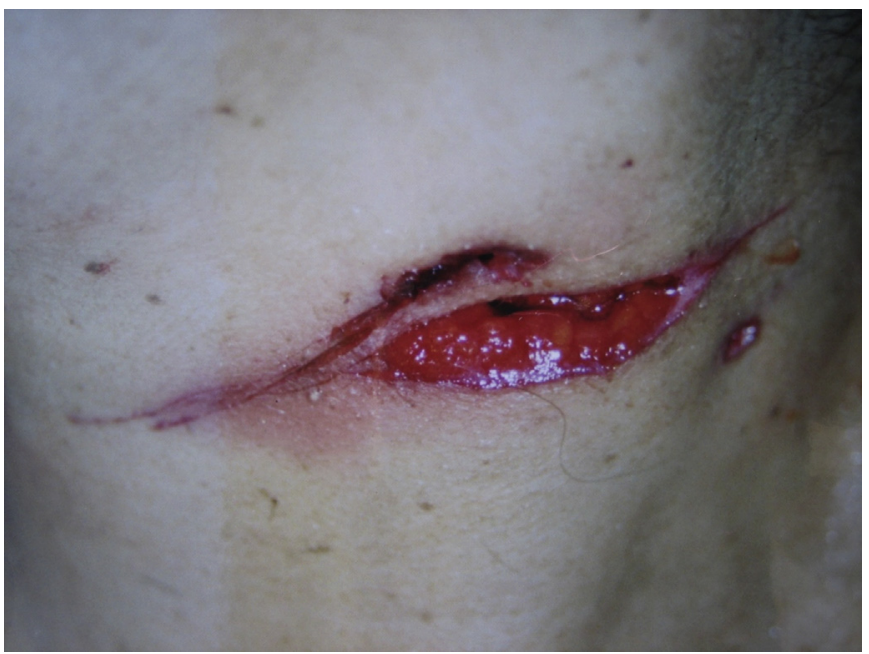

Fig. 2. Close-up of the stab wounds on the left side of the neck

were also found on the wall of the basement just behind the copy machine where a second point of convergence was identified, close to an electric plug corresponding to the area where the first assault probably occurred. The suspect for this homicide was her son-in-law, a 40 years old man, right-handed individual who first discovered the corpse and called the emergency service. Based on the evidence collected by blood pattern analysis at the scene and 


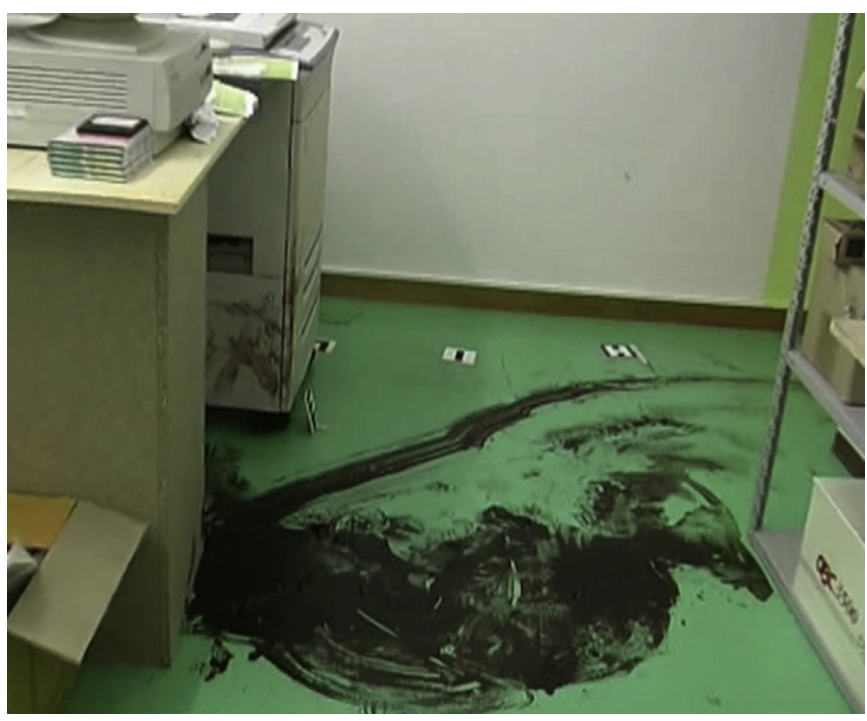

Fig. 3. The drag pattern showing movement across blood pooling on the floor, close to a first point/area of convergence or blood source where the person was assaulted.

on the blood-stained clothing worn by the suspect, the man was charged with the murder of her mother-in-law. The suspect never confessed the crime. He said the bloodstains on his clothing were just blood transfer patterns related to the contact with the victim when he tried to help the lady. But serious inconsistencies with this version of events were found based on some medium velocity impact blood spatter observed also on his pants and shirt. The investigation raised also the possibility that an additional victim could have been killed by the man. In fact, during the police interrogation the man said that this was the second time he found a cadaver exactly as occurred three years before at home with his father. He also said that based on his previous experience, the lady could have died falling down stairs exactly as occurred to his father three years before.

\subsection{Case 2}

On October 2009 the suspect found dead his 70 years old father at the bottom of a bloodstained basement stairwell. Some bloodstains were observed on the floor and the wall as well as on some roof tiles located on one side of the stairwell. Unfortunately, at that time no blood pattern analysis and forensic autopsy were performed. In fact, the case was closed as accident based on two post-mortem (PM) external body examinations. Although the results of these PM exams were different and contradictory, no forensic autopsy was officially requested. A preliminary external body examination made by a general practitioner recorded injuries suspicious to be stab wounds to the right side of the neck and thorax correctly requesting a forensic autopsy. Surprisingly the Judicial Authority requested an additional external body examination without subsequent autopsy. This second survey made by a physician specialized in legal medicine (not a forensic pathologist) certified that all the injuries were consistent with blunt trauma occurring falling down stairs. Therefore, the manner of death was declared as accident. Unfortunately the external injuries were not documented diagrammatically and photographically by this second expert. The external examination was neither followed by an X-ray nor CT scan. No comparison of the medical findings with the results from the death scene was performed by Police Officers neither requested by the Judicial Authority. Only the exhumation of the body (three years later, and after the murder of the lady) confirmed the diagnostic hypothesis raised by the general physician thanks to the remarkable good state of preservation of the body, buried in a sealed metal coffin. The elderly man was found to have been stabbed multiple times in the neck and thorax (Fig. 4). A total of eleven sharp force injuries were detected: three stab wounds on the right side of the neck, three incised wounds and one stab wound on the right shoulder, three stab wounds on the anterior right side of the thorax. Finally a defense wound was also found on the right hand. It was not so difficult to identify the sharp force injuries because of the skin was so well preserved that some stab wounds showed still their sharp and blunt angles (consistent with a single-edge blade) as well as signs of hemorrhage of soft tissues surrounding the internal tracks. However, among the multiple stab wounds only two injuries on the right side of the neck were lethal as they were deep enough to damage the carotid sheath and in particular the common carotid artery, just before the bifurcation. The 40 years old son was finally condemned to life in prison for double murder. The inheritance money was the main motivation for the murders. In the past the man has been already condemned for crimes against property as he was always in search of money from his relatives and friends due to financial problems. No psychiatric disorder was found and the man was declared imputable.

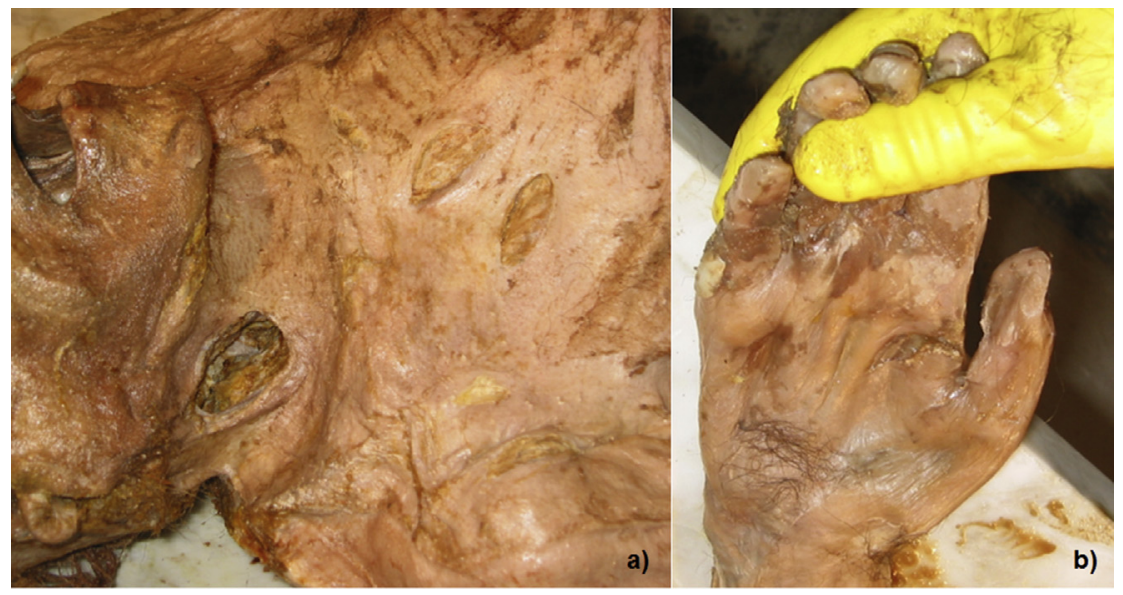

Fig. 4. The exhumation findings: a) multiple stab wounds to the neck and thorax, b) defense wound on the right hand. 


\section{Discussion}

Although parricide is a rare form of murder, the prompt detection and conviction of the perpetrator in this case would have prevented the killing of the lady, which was for the same financial motivation that moved the son to kill his father three years before. To prevent or reduce the risk that an offender continues to commit crimes is one of the main purposes of forensic science. Unfortunately, this target was totally failed in the present death investigation because of the absence of a forensic autopsy, although there were discrepancies between two different and contradictory PM external examinations.

A primary task of any medico-legal death investigation is the reliable estimation of the cause and manner of death. Despite modern imaging techniques, the autopsy along with all information available coming from the medical history, scene survey and circumstances of the death, is still considered the gold standard for determining the cause and manner of death. ${ }^{18}$ The risk of misclassification is high when a cause/manner of death is not supplemented with data from autopsy and scene survey. A retrospective study on death certificates found that $34 \%$ of the cases had no proximate or a totally wrong cause/manner of death. ${ }^{19}$ Similarly, based on the analysis of 155 consecutive forensic exhumations, major deviations between the cause of death as stated on the death certificate and as diagnosed after autopsy were revealed in $37 \%$ of cases with emphasis on undetected homicides. ${ }^{20}$ It has been assumed that in Germany around 1.200 homicides a year remain unidentified on death certificates because of missing forensic autopsy. $^{21}$

According to previous studies the accuracy of the cause of death as recorded on death certificates has been analyzed in trauma deaths resulting in a frequency of unrecognized injuries of $11 \%$ of all cases. ${ }^{22}$ However, in the literature the percentage of missed injuries discovered at autopsy after traumatic death can be higher than that, going up to $68 \%{ }^{23-25}$ Minor as well as severe missed injuries can be often discovered at autopsy. In this regard the autopsy after traumatic death is more than a mechanism of quality control since it may be important to the surviving family, or have public health implications. ${ }^{23}$ Unfortunately the majority of trauma and violent deaths are still certified without an autopsy because of cost containment and increased confidence in modern imaging techniques. ${ }^{18,21,26,27}$ Therefore, misdiagnoses as well as misinterpretation of medical findings are inevitable.

The forensic pathology community is aware that significant discrepancies between external body examination and forensic autopsy are not rare. The level of expertise provided by the physician involved in death investigation as well as the bad conditions of examination can often explain such discrepancies. ${ }^{28}$ However, this is not always true since even qualified physicians can fail. In the case illustrated above, the second physician was specialized in legal medicine (not a forensic pathologist) and, therefore, more familiar with injuries and cadavers compared with the first physician (general practitioner) involved in the death investigation. But the general practitioner better realized the real purpose of the PM external examination. According to Madea and Rothschild, ${ }^{21}$ the main scope of a PM external examination is not just to establish medical diagnoses, but to provide facts in the service of the judicial process and the public interest. Also medical examiners and coroners have a high rate of error up to $28 \%$ in determining cause and manner of death if an autopsy is not performed, especially in apparent natural deaths. ${ }^{29,30}$ The majority of errors has reported to be the result of an overdiagnosis of coronary heart disease, hypertensive cardiovascular disease, and cancer. ${ }^{28,30}$ Therefore, the cause of death based on external examination can be mostly erroneous not only in cases classified as natural but also in trauma deaths. In the present undetected patricide, the qualified physician failed to recognize multiple stab wounds to the neck and thorax, misinterpreted as injuries which had occurred as the result of accidental blunt trauma (falling down stairs).

Differentiation between a stab wound and a laceration is relatively easy on fresh bodies compared with decomposed bodies and should be basic for every physician. ${ }^{31,32}$ It is extremely important to provide such differentiation since they are caused by different traumatic mechanisms represented respectively by pointed and sharp-edged instruments (stab wounds), and blunt force impact (lacerations). Therefore, careful examination of the surface and depth of the wound is required in order to reveal at least the diagnostic features of a laceration (such as some abrasion or contusion of the irregular margin or bridges of tissue in the depth of the wound running from side to side) or a stab wound (i.e. sharp edges and regular margin, commonly without abrasion or contusion, depth of the wound track in the body exceeding its length in the skin). The lack of such basic knowledge and procedure of differential diagnosis can explain the misinterpretation of the medical findings by the second expert who failed also to document the external injuries both diagrammatically and photographically. ${ }^{33}$ Surprisingly he did not pay attention also to the high number of wounds (eleven in total) and their distribution (mainly located on the right side of the neck and thorax), in some studies described as typical features of homicidal sharp fatalities. ${ }^{34-36}$ Although strongly suggested, ${ }^{37}$ no comparison of the medical findings with the results from the death scene survey, such as a blood stain analysis was requested either by the second so-called expert or from the Police Officers or the Judicial Authority.

We found the undetected patricide a quite representative case of the Italian death investigation system commonly performed by individuals with no specific training and not run professionally. Unfortunately in Italy majority of traumatic and violent deaths are certified without autopsy and this seems to occur also in those countries where external examination of the body is the most common method used to investigate medico-legal deaths or where investigation can proceed with a forensic autopsy only if a crime is suspected or the manner of death is unclear. ${ }^{18,21,38}$ In Italy a significant amount of medico-legal investigations (especially for deaths resulted from trauma following suicide or accidental events like motor vehicle crashes, domestic or occupational accidents) are restricted to an external body examination without subsequent autopsy and/or a crime scene survey even if the event is uncertain. We are talking about $4-5 \%$ of all deaths (approximately 580.00 per year) which means with an optimistic estimation there are at least some thousand of forensic autopsies per year that should be performed in every traumatic and violent case. Although the virtopsy approach is spreading fast around the world, ${ }^{39,40}$ in Italy most of the PM external examinations are still neither followed by CT scan nor blood samples for toxicological analysis. Italian legislation on death investigation says that non judicial autopsies and forensic autopsies should be managed by different institutions, respectively National Health Service for non judicial autopsies and Judicial Authority for forensic autopsies. However, the critical point is that forensic autopsies can be requested only by the Prosecutors. The Prosecutor has absolute authority to request an autopsy and to choose his own expert. Forensic autopsy is not mandatory even if the manner or cause of death is unclear or is suspicious, especially if a physician certifies a cause/manner of death of no interest to the Judicial Authority or there are no relevant findings from the PM external examination. 
Furthermore, even physicians not trained in death investigation can be appointed as experts and be requested to perform an external examination of the body as well as an autopsy, where they may easily misinterpret the medical findings.

Great disparities and differences in legislation on cause and manner of death and related existing operations can explain the low autopsy rate in violent and undetermined deaths in some other European Countries apart from Italy. ${ }^{38}$ This happens in violation of the Recommendation No. R 99 of the Committee of Ministers (Council of Europe) adopted since $1999^{41,42}$ but only partially applied in several European Countries. The main scope of the recommendation dealing with the harmonization of medico-legal autopsy rules in Europe was to underline the following principles and procedures: a) in cases where death may be due to unnatural causes, the competent Authority, accompanied by one or more medico-legal experts, should where appropriate investigate the scene, examine the body and decide whether an autopsy should be carried out; b) autopsies should be carried out in all obvious or suspected unnatural deaths, even where there is a delay in causative events and death, in particular including occupational, transportational or domestic accidents, suicides or suspected suicides, homicides or suspected homicides, sudden unexpected deaths. The undetected patricide is a clear example of what can happen if the above principles are missing and the procedures suggested are not followed.

\section{Conclusion}

Although misinterpretation of external lesions is inevitable and significant discrepancies between the external body examination and forensic autopsy are not rare, in the case of contradictory results of post-mortem external examinations or unclear/suspicious cause and manner of deaths, investigation should proceed necessarily with a forensic autopsy.

Unfortunately, in Italy there is no official system of peer-review or a method of quality improvement to re-check post-mortem external examinations. Standard operating procedures covering quality assurance in death certification or implemented policy to evaluate the performance or the inaccuracy of the certifier could be beneficial to medico-legal offices as well as to medical practitioners involved in death investigations. More efforts should still be made in order to improve the quality, completeness, efficacy, and management of forensic sciences including medico-legal death investigation in Italy as well as in other countries. In fact, some chronic weaknesses of death investigation systems are quite common worldwide ${ }^{43}$ among which the various and different legislations concerning death certification, the high risk of missing autopsy and misinterpretation of medical findings. These concerns on the practice of death investigation can be easily addressed if all suspected traumatic and violent deaths could be really investigated with a forensic autopsy and a scene survey. Many crimes could be solved just in time preventing the risk of misdiagnosis of external injuries and, therefore, additional homicides like occurred in the present undetected patricide. In this regard, the forensic autopsy is still a reliable form of quality control to be adopted with various potential implications on the public health and judicial system.

\section{Conflict of interest}

There are no conflicts of interest.

\section{Funding}

The article was not funded by any funding body or institution.
Ethical approval

The article has been carried out according to Ethics in Publishing.

\section{References}

1. Heide KM. Understanding parricide: when sons and daughters kill parents. New York: Oxford University Press; 2013.

2. Heide KM, Boots DP. A comparative analysis of media reports of U.S. parricide cases with officially reported national crime data and the psychiatric and psychological literature. Int J Offender Ther Comp Criminol 2007;51: 646-75.

3. Eurostat. Crime statistics. January 2014. http://epp.eurostat.ec.europa.eu/ statistics explained/index.php/Crime statistics [accessed 30.10.14]

4. Federal Bureau of Investigation. Crime in the United States. Washington, DC: Department of Justice; 2012. http://www.fbi.gov/about-us/cjis/ucr/crime-inthe-u.s/2012/crime-in-the-u.s.-2012 [accessed 30.10.14]

5. Shon CH, Targonski JR. Declining trends in U.S. parricides, 1976-1998: testing the Freudian assumptions. Int J Law Psychiat 2003;26:387-402.

6. Heide KM. Matricide and stepmatricide victims and offenders: an empirical analysis of U.S. arrest data. Behav Sci Law 2013;31:203-14.

7. Heide KM. Patricide and steppatricide victims and offenders: an empirical analysis of U.S. arrest data. Int J Offender Ther Comp Criminol 2014;58: $1261-78$.

8. $25^{\circ}$ Rapporto Italia. EURISPES (Istituto di Studi Politici, Economici e Sociali). 2013. http://www.eurispes.eu/content/rapporto-italia-2013-0 [accessed 30.10.14].

9. Ministero dell'Interno della Repubblica Italiana. In: Barbagli M, Colombo A, editors. Rapporto sulla criminalità e la sicurezza in Italia, 2010. Milano: Il Sole 24 Ore; 2011. http://www.interno.gov.it/mininterno/export/sites/default/it/ assets/files/21/0501_sintesi_rapporto_icsa.pdf [accessed 30.10.14].

10. West SG, Feldscher M. Parricide: characteristics of sons and daughters who kill their parents. Curr Pshyc 2010;9:20-38.

11. Dantas S, Santos A, Dias I, Dinis-Oliveira RJ, Magalhaes T. Parricide: a forensic approach. J Forensic Leg Med 2014;22:1-6.

12. Heide KM. Why kids kill parents: child abuse and adolescent homicide. Columbus: Ohio State University Press; 1992.

13. Marleau JD, Auclair N, Millaud F. Comparison of factors associated with parricide in adults and adolescents. J Fam Viol 2006;21:321-5.

14. Diem C, Pizarro JS. Social structure and family homicides. J Fam Viol 2010;25: $521-32$.

15. Grattagliano I, Greco R, Di Vella G, Campobasso CP, Corbi G, Romanelli MC, et al. Parricide, abuse and emotional processes: a review starting from some paradigmatic cases. Clin Ter 2015;166:e47-55.

16. Heide KM, Petee TA. Weapons used by juveniles and adult offenders in US parricide cases. I Interpers Violence 2007:22:1400-14.

17. Bourget D, Gagne P, Labelle ME. Parricide: a comparative study of matricide versus patricide. J Am Acad Psychiatry Law 2007;35:306-12.

18. Gill JR, Scordi-Bello IA. Natural, unexpected deaths: reliability of a presumptive diagnosis. J Forensic Sci 2010;55:77-81.

19. Pritt BS, Hardin NJ, Richmond JA, Shapiro SL. Death certification errors at an academic institution. Arch Pathol Lab Med 2005;129:1476-9.

20. Karger B, de la Grandmaison GL, Bajanowski T, Brinkmann B. Analysis of 155 consecutive forensic exhumations with emphasis on undetected homicides. Int J Leg Med 2004;118:90-4.

21. Madea B, Rothschild M. The post-mortem external examination. Dtsch Arztebl Int 2010;107:575-88.

22. Sharma BR, Gupta M, Bangar S, Singh VP. Forensic considerations of missed diagnoses in trauma deaths. J Forensic Leg Med 2007;14:195-202.

23. Light TD, Royer NA, Zabell MD, Le MB, Thomsen TA, Kealey GP, et al. Autopsy after traumatic death. A schifting paradigm. J Sur Res 2009:1-4.

24. Sharma BR, Gupta M, Harish D, Singh VP. Missed diagnoses in trauma patients vis-à-vis significance of autopsy. Injury 2005;36:976-83.

25. Stothert JC, Gbaanador GBM, Herndon DN. The role of autopsy in death resulting from trauma. J Trauma 1990;30:1021-5.

26. O'Grady G. Death of the teaching autopsy. BMJ 2003;327:802-3.

27. Royal College of Pathologists of Australasia Autopsy Working Party. The decline of the hospital autopsy: a safety and quality issue for healthcare in Australia. Med J Aust 2004;180:281-5.

28. de la Grandmaison GL, Fermanian C, Durigon M. Analysis of discrepancies between external body examination and forensic autopsy. Am J Forensic Med Pathol 2008;29:40-2.

29. Nashelsky MB, Lawrence $\mathrm{CH}$. Accuracy of cause of death determination without forensic autopsy examination. Am J Forensic Med Pathol 2003;24:313-9.

30. Vanatta PR, Petty CS. Limitations of the forensic external examination in determining the cause and manner of death. Hum Pathol 1987;18:170-4.

31. Di Maio VJ, Di Maio D. Forensic pathology. 2nd ed. Boca Raton, FL: CRC Press; 2001.

32. Saukko P, Knight B. Knight's forensic pathology. 3rd ed. New York: Arnold Press; 2004

33. Dolinak D, Matshes EW, Lew EO. Forensic pathology. Principles and practice. Burlington, USA: Elsevier; 2005.

34. Mazzolo GM, Desinan L. Sharp force fatalities: suicide, homicide or accident? A series of 21 cases. Forensic Sci Int 2005;147S:S33-5. 
35. Gill JR, Catanese C. Sharp injury fatalities in New York City. J Forensic Sci 2002;47:554-7.

36. Brunel C, Fermanian C, Durigon M, de la Grandmaison GL. Homicidal and suicidal sharp force fatalities: autopsy parameters in relation to the manner of death. Forensic Sci Int 2010;198:150-4.

37. Karger B, Rand S, Fracasso T, Pfeiffer H. Bloodstain pattern analysis-casework experience. Forensic Sci Int 2008;181:15-20.

38. Ylijoki-Sørensen S, Boldsen JL, Boel LW, Bøggild H, Lalu K, Sajantila A. Autopsy rate in suicide is low among elderly in Denmark compared with Finland. Forensic Sci Int 2014;244C:158-65.

39. Thali MJ, Dirnhofer R, Vock P. The virtopsy approach. 3D optical and radiological scanning and reconstruction in forensic medicine. Boca Raton, FL: CRC Press; 2009 .
40. O'Donnell C, Woodford N. Post-mortem radiology - a new sub-speciality? Clin Radiol 2008:63:1189-94.

41. Council of Europe Committee of Ministers. Recommendation of the committee of ministers to member states on the harmonization of medico-legal autopsy rules European Union 1999 [Report No.: R (99) 3]. 1999., http://www.coe.int/t/dg3/ healthbioethic/texts_and_documents/RecR(99)3.pdf [accessed 30.10.14].

42. Brinkmann B. Harmonization of medico-legal autopsy rules. Committee of Ministers. Council of Europe. Int J Legal Med 1999;113:1-14.

43. Testimony of Gregory A. Schmunk (NAME President) to US Senate Committee on Commerce, Science, and Transportation on June 26, 2013. 2013. http://www.cap. org/apps/docs/statline/pdf/schmunk_testimony.pdf [accessed 30.10.14]. 